\title{
Simulation Study on the Design-number of Twin Vane Spin Core Nozzle
}

\author{
Su-Ping Ma \\ Zhejiang Industry Polytechnic College \\ Shaoxing, China, 312000,13616855628 \\ msp889@sohu.com
}

\author{
Qi-Feng Gao \\ Zhejiang Industry Polytechnic College \\ Shaoxing, China, 312000
}

\begin{abstract}
When designing twin vane spin core water atomizing nozzle, it should have an appropriate ratio between the cavity aperture and the exit diameter of nozzle, we call it design-number. It not only affects the spray spread angle, also affects the flow passage size of the nozzle internal at the spin core. Analysis by synthesis, the ratio selected 4.1 is able to combine these two factors. At this point, the lateral dimension of the internal spin channel is not less than the exit diameter. With CFD numerical simulation infer the spray spread angle can reach about $50^{\circ}$. The design-number of 4.1 may be taken as design dimensionless number of tiny exit diameter nozzle. Further simulation study shows that in the same of the nozzle cavity aperture, with the nozzle exit diameter increases, the spray spread angle increases, it is approximately direct proportion to the nozzle exit diameter within the range of $1 \sim 2.5 \mathrm{~mm}$. Testing $1.5 \mathrm{~mm}$ and $2.0 \mathrm{~mm}$ exit diameter nozzle, it confirms the simulation results.
\end{abstract}

Key words-Twin vane spin core; Spray spread angle; CFD simulation

\section{INTRODUCTION}

For spraying water atomizing nozzle on dust fall, twin vane spin core nozzle is suitable for that water quality is not very clean working conditions [1]. Researchers used the PDPA laser equipment to determine and study the atomization performance of this type of nozzle, the droplet diameter can be less than $100 \mu \mathrm{m}$ in $2 \mathrm{MPa}$ spray pressure [2], which is suitable for settling fine dust particles [3]. Hence, more and more it is used in the workplace of underground coal mine. Spray system design usually needs to predict the parameters of a single nozzle such as spray spread angle, because big spray spread angle means that the spray coverage area is big too. The nozzle structure size affects its atomization effect (including the spray spread angle), also affects its ability of the anti-water pollution, thus affects the spray system reliability. Therefore, it is an important factor that the nozzle structural design be or be not reasonable, in which the more important factor is the relationship between the cavity aperture and the exit diameter of nozzle. By structural analysis to determine an appropriate ratio, then for the nozzle model, using numerical simulation technique to analysis the liquid flow field inside the nozzle and study its performance, to estimate the spray spread angle, and further to study the intrinsic link between the nozzle spray spread angle and its exit diameter. The research results will have help effect for rational design of the spray dust suppression system.

\section{The Design-NUMBer of Twin VANE SPIN CORE NOZZLE}

Fig. 1 shows the three-dimensional schematic of twin vane spin core atomizing nozzle, it is composed of the nozzle casing and the rotating core. Twin vane spin core and nozzle cavity form two isosceles triangle orifice, liquid through the two triangular holes along spiral vane generate rotational flow under pressure. The greater the rotational flow strength of liquid in the nozzle, the bigger the spray spread angle, and the spray stream maintaining a certain amount rotational movement is conducive to the atomization of the liquid [4]. The two triangular holes flow area should not be large. Otherwise the swirl kinetic energy is not enough make liquid spray diffusion.

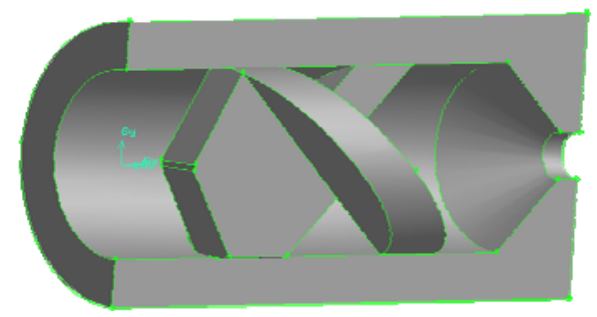

Figure1.Twin van spin core nozzle

In practice, we found that under the premise of the nozzle exit diameter not changed, the larger the cavity aperture of nozzle, the smaller the spray spread angle; and the smaller the cavity aperture, the lager the spray spread angle. Therefore, in order to obtain a larger spray spread angle, the nozzle cavity aperture design should be as small as possible. The size of the nozzle cavity aperture have an impact not only on the spray spread angle, also on the triangular orifice flow area at structure, which related to the reliability of the nozzle work for water containing particles of certain impurities, so the size of the nozzle cavity aperture become an important factor.

The nozzle design should take into account the spray spread angle and reliability requirements. In order to reduce the possibility of nozzle clogging, in accordance with the principle that the internal flow cross-section diameter of the triangular orifice is not less than the nozzle exit diameter, the design sketch map is shown in Fig.2 And so the impurity particles of less than the nozzle exit diameter size in water are not detained inside the nozzle to form a blockage. In addition, 
the thickness $b$ and the helix angle $\beta$ of the spin vanes also affect the size of the triangular orifice. Taking into account the strength requirements, take $b$ equal $d$. The helix angle $\beta$ equals $40^{\circ}$ [5]. Through detailed calculating, the ratio between the nozzle cavity aperture $\mathrm{D}$ and the exit diameter $\mathrm{d}$ is $\mathrm{D} / \mathrm{d}$ equal 4.1 , we call it design number. Other geometric dimensions are determined as follows: the nozzle exit length h equals $0.5 \mathrm{~d}$; the contraction angle of the conical $\gamma$ equals $90^{\circ}$, the length $\mathrm{H}$ equals $0.5 \mathrm{D}$, this length is for making the rotating liquid rectification, especially when processing the twin vane spin core is not completely symmetrical, after rectification, the liquid rotating movement is uniform, after contraction and spray, the atomizing diffusion is also uniform.

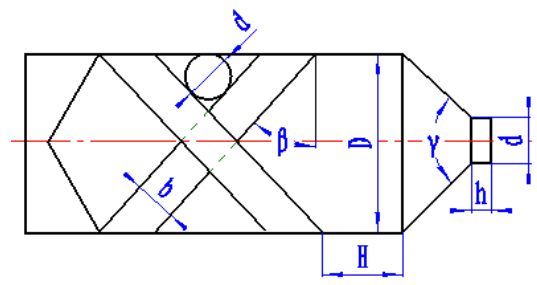

Figure2. Nozzle size sketch map

For spray dust suppression nozzles, the spray spread angle is an important indicator, so that it can be predicted by using software emulation.

\section{NOZZLE DyNAMICS SimUlation}

Using FLUENT software is for dynamic simulation of the nozzle. Liquid flow in the nozzle is turbulent motion, so using the RNG k- $\varepsilon$ model simulation is suitable, because it is more generality in the turbulent operation [6].

Taking the nozzle of $2 \mathrm{~mm}$ exit diameters as the simulation object, its each part of the geometric dimensions is respectively that $\mathrm{d}=2 \mathrm{~mm}, \mathrm{~h}=1 \mathrm{~mm}, \mathrm{D}=8.2$ (the actual 8) $\mathrm{mm}, \mathrm{H}=4 \mathrm{~mm}, \mathrm{~b}=\mathrm{d}=2 \mathrm{~mm}, \beta=40^{\circ}, \gamma=90^{\circ}$.

Using FLUENT pre-processing software GAMBIT creates the nozzle three-dimensional calculation model. Fig.3 shows the meshing of the calculation model, which adopting the tetrahedral mesh. So it has 371,937 units and 69387 nodes.

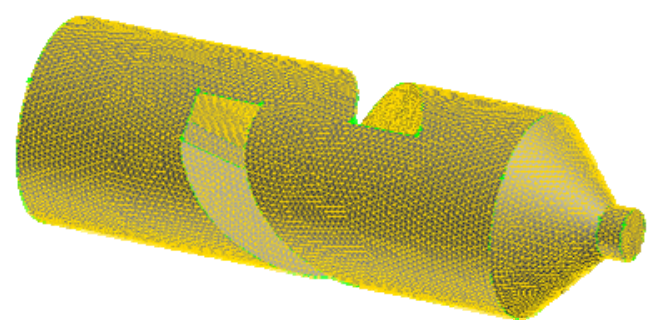

Figure3. Nozzle model grid plot

In the calculation model, the entrance of the boundary conditions is spray water pressure, and the export is atmospheric pressure, others are solid wall. In Parameter settings, there are two important datum of the turbulent kinetic energy $\mathrm{k}$ and dissipation rate $\varepsilon$ need to calculate [7]. Selecting $3 \mathrm{MPa}$ (mining shearer sprays require pressure) to be spray inlet water pressure, according to the $2 \mathrm{~mm}$ exit diameter nozzle actual water consumption is $\mathrm{Q}=151.67 \mathrm{~cm}^{3} / \mathrm{s}$, from which we calculate its import value $\mathrm{k}=0.0278, \varepsilon=1.36$ and export value $\mathrm{k}=5.1, \varepsilon=13.52 \times 10^{3}$. The iterative calculation time is 257 to reach the 0.001 convergence value set.

\section{SimUlATION RESUlTS ANALYSIS 0F NOZZLE}

Through the visualization capabilities of the FLUENT software the flow state of liquid inside the nozzle can be display. Fig. 4 shows the flow pattern of the liquid behind the twin vane spin core in the nozzle. The liquid flow form two helical flows when it outflow from two triangle orifice, the helical flows get corrected in a straight segment and then contract to nozzle outlet. On the basis of the simulation results, using scatter plots show the changes about flow velocity of the liquid in the nozzle. As shown in Fig.5 is the flow velocity $u_{x}$ (along the nozzle axis $\mathrm{x}$ direct) change curve in the $\mathrm{y}$ and $\mathrm{z}$ axis on the combine section of the cylindrical segment and conical segment. Fig. 6 shows the y direction velocity $u_{y}$ in the $z$-axis at the same section, and so does $u_{z}$ in the y-axis, in fact which shows a variation curve of circumferential linear velocity. On this section the axial velocity is biggest on the center and the circumferential velocity is biggest near the edge. Fig. 7 and Fig. 8 showing the change curve in velocity is on the cross-section of nozzle exit. In the Fig. 7 the difference of the flow velocity along the $\mathrm{x}$ (nozzles axis) direction is not big between center and edge. Fig. 8 shows the circumferential linear velocity on the export section, it shows a linear regular change along the radius. If the axial velocity and tangential velocity are combined, the absolute velocity is towards equilibrium on the section.

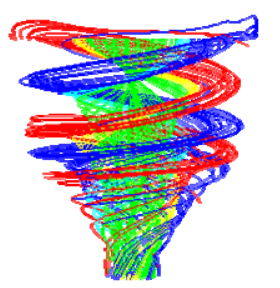

Figure4. Flown line in nozzle

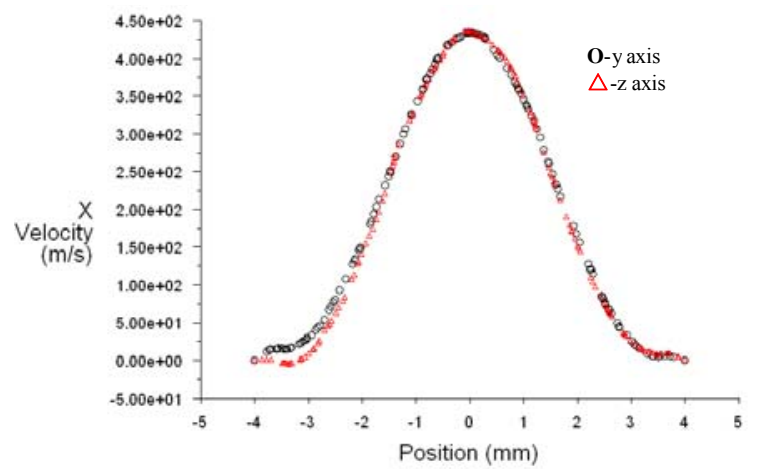

Figure5. Axes velocity variety curve on joint section of column and cone 


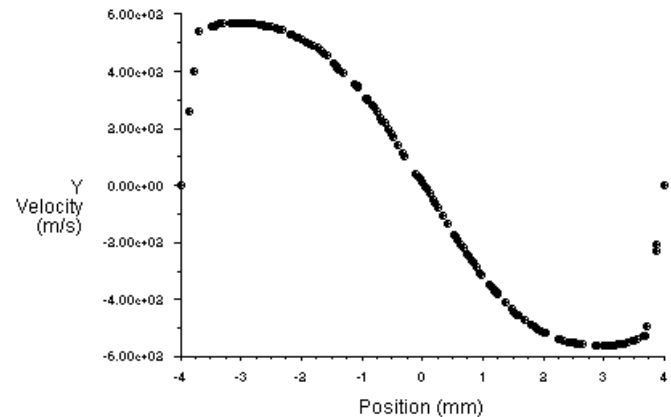

Figure6. Circumference velocity variety curve on joint section of column and cone

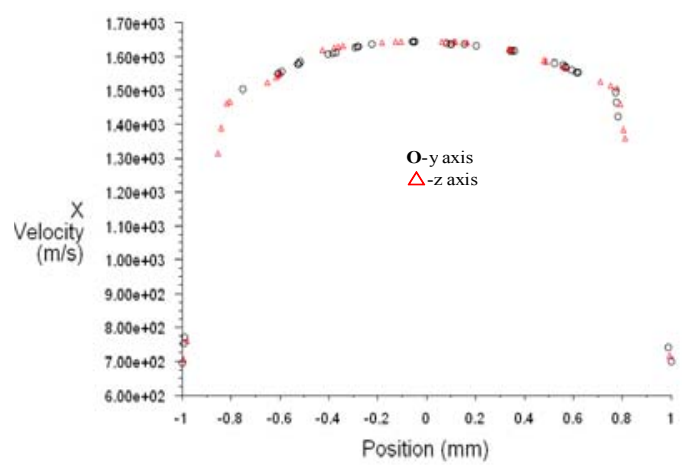

Figure7. Axes velocity variety curve on exit section of nozzle

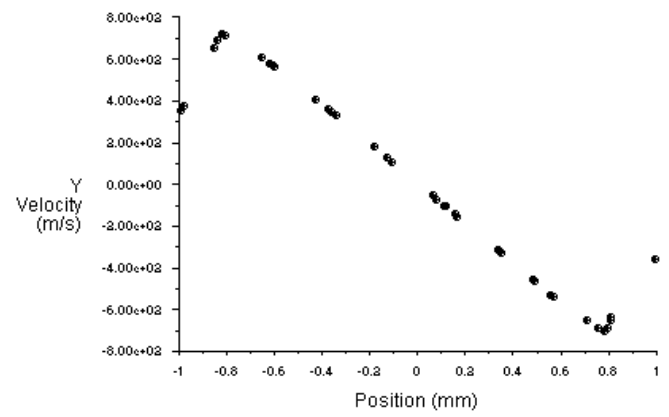

Figure8. Circumference velocity variety curve on exit section of nozzle

With on the basis of Fig. 8 data, in accordance with the ratio of the maximum circumferential velocity and the axial velocity on the corresponding point we can calculate the spray diffusion angle $\alpha$, it is about $50^{\circ}$. The actual ratio of the cavity aperture and exit diameter of the nozzle is 4.0. If only the nozzle exit diameter becomes $1.5 \mathrm{~mm}$, corresponding outlet length h equals $0.75 \mathrm{~mm}$, other are all invariant, the ratio of the nozzle's cavity aperture and the exit diameter is 5.33, through the simulated spray spread angle is about $30^{\circ}$.

From actual survey, $1.5 \mathrm{~mm}$ exit diameter nozzle is used in spraying dust fall more often. For $1.5 \mathrm{~mm}$ exit diameter nozzle, according to the ratio of 4.1 to calculate the cavity aperture is $6.15 \mathrm{~mm}$. Thus the nozzle geometric dimensions are respectively: $d=1.5 \mathrm{~mm}, \mathrm{~h}=0.75 \mathrm{~mm}, \mathrm{D}=6.5 \mathrm{~mm}, \mathrm{H}=3 \mathrm{~mm}$, $\mathrm{b}=\mathrm{d}=1.5 \mathrm{~mm}, \beta=40^{\circ}$ and $\gamma=90^{\circ}$. At $3 \mathrm{MPa}$ spray pressure simulation, the spray spread angle $\alpha$ is about $47^{\circ}$.
In order to analyze the impact of the different nozzle exit diameter effect on spray spread angle, using the $1.5 \mathrm{~mm}$ diameter nozzle geometry as a computational model, exit diameter respectively is other number and exit length is $1 / 2$ of the exit diameter. Through the simulation the spray spread angle and different exit diameter is shown in Table 1, in which the spray spread angle increases with the exit diameter larger and decreases with the exit diameter smaller.

\section{TABLE 1 DIFFERENT CALIBER NOZZLE SPRAY ANGLE}

\begin{tabular}{lcccccc}
\hline Nozzle exit diameter d(mm) & 1.0 & 1.2 & 1.5 & 1.75 & 2.0 & 2.25 \\
\hline Design-number D/d & 6.5 & 5.4 & 4.3 & 3.7 & 3.3 & 2.9 \\
\hline Spray spread angle $\alpha$ & $30^{\circ}$ & $38^{\circ}$ & $47^{\circ}$ & $57^{\circ}$ & $64^{\circ}$ & $70^{\circ}$ \\
\hline
\end{tabular}

\section{EXPERIMENT OF NOZZLES}

In the laboratory we tested and determined the exit diameter of $1.5 \mathrm{~mm}$ and $2 \mathrm{~mm}$ nozzle, which their cavity aperture is all $6.5 \mathrm{~mm}$. Fig. 9 is the picture of $1.5 \mathrm{~mm}$-exit diameter nozzle under $3 \mathrm{MPa}$ hydraulic pressure spray testing, the spray fog stream is solid cone-shaped diffusion, and then it becomes solid cylindrical type. The data of the two nozzle testing are shown in Tables 2 and 3, from which we see large exit diameter nozzle has bigger spray cross section.

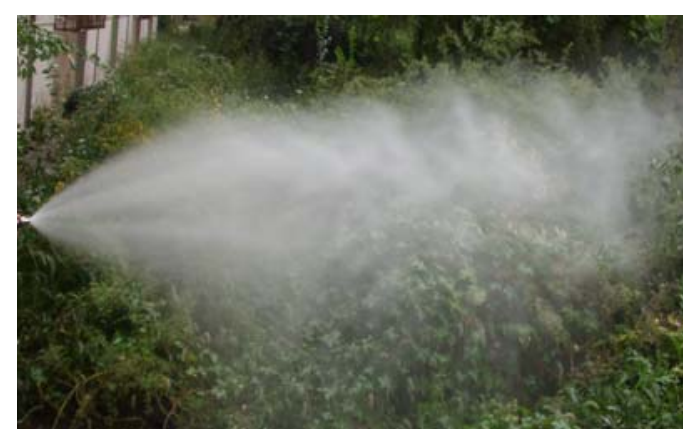

Figure9. Spray test of $1.5 \mathrm{~mm}$ diameter nozzle

TABLE 2 WATER-FOG FLOW SIZE AT 1.5MM DIAMETER NOZZLE

\begin{tabular}{lccccccc}
\hline Supply pressure(MPa) & 1 & 2 & 3 & 4 & 5 & 6 & 7 \\
\hline Spray cone length(m) & 0.8 & 0.85 & 0.9 & 0.95 & 1.0 & 1.1 & 1.2 \\
\hline Spray column diameter(m) & 0.75 & 0.8 & 0.8 & 0.8 & 0.8 & 0.8 & 0.8 \\
\hline Spray total length(m) & 3.0 & 3.4 & 3.8 & 4.1 & 4.5 & 4.8 & 5.0 \\
\hline
\end{tabular}

TABLE 3 WATER-FOG FLOW SIZE AT 2.0MM DIAMETER NOZZLE

\begin{tabular}{lccccccc}
\hline Supply pressure(MPa) & 1 & 2 & 3 & 4 & 5 & 6 & 7 \\
\hline Spray cone length(m) & 0.9 & 0.95 & 1.0 & 1.0 & 1.1 & 1.2 & 1.3 \\
\hline Spray column diameter(m) & 1.1 & 1.2 & 1.2 & 1.2 & 1.2 & 1.2 & 1.2 \\
\hline Spray total length(m) & 3.0 & 3.3 & 3.7 & 4.0 & 4.3 & 4.7 & 4.9 \\
\hline
\end{tabular}


From Tables 2 and 3 using the test data under $3 \mathrm{MPa}$ pressure to approximate calculate the spray spread angle, it is about $48^{\circ}$ and $62^{\circ}$, which has only about $3.2 \%$ deviation compare with the simulation results. See in the table, the fog spray diameter of the cylindrical section is basically unchanged, that is, for certain structural dimensions nozzles, the spray mist flow cross-sectional area is unchanged. However, as the spray pressure increases, the length of the cone segment increases, so that the spray angle is contracted and the spray mist flow full-length is longer.

\section{DISCUSSION}

Shown in Fig. 4 reproduce intuitively the flow state of the liquid in the nozzle, Fig. 5 and 6 reflect the different flow rate of liquid in one of the section with the numerical. The strength of circumferential linear velocity direct impacts on the circumferential linear velocity value of the liquid moving to the nozzle exit, and then affecting the spray spread angle. Fig. 7 shows the axial velocity when the liquid is about to spray, it impacts the move speed of the droplets after the liquid emission, thus affecting the atomization level of the droplets. Fig. 8 shows the circumferential velocity of the liquid spray, it directly affects the spray spread angle and also plays a role on the droplet atomization. Nozzle design according to the 4.1 of design-number, the circumferential velocity have certain values when the liquid spray, and thus the spray spread angle can reach about $50^{\circ}$. See from Table 1 , the smaller the ratio is, the greater the spray spread angle reach. This is because the smaller the design-number is, the stronger the spin flow extent of liquid flow in the nozzle is, which make the circumferential velocity of liquid have bigger proportion at nozzle exit.

For small exit diameter nozzle, such as the following exit diameter of $1.5 \mathrm{~mm}$ nozzle, should take the design number of 4.1 as the minimum design number. Less than it, the triangle spin channel in nozzle is smaller than its exit diameter, may be the small particles close to the nozzle exit diameter size clog in the triangle spin channel, nozzle become useless, and then scrapped. The large exit diameter nozzle can be appropriate to reduce this design number to obtain larger spray spread angle. Although it makes the internal spin channel flow area less than the exit, because the overall size is big, the absolute size of the internal channel flow area is not too small.

Nozzle spray dust suppression system mostly need many nozzles work simultaneously. Total consumption of water, spray pressure, nozzle number, a single nozzle spray spread angle and water consumption, etc. form a multi-factor problem.
Knowing well the characteristics of the nozzle is benefit to design a reasonable spray dust suppression system.

Nozzle atomization performance is related to a number of factors. This article only focused on the design-number of twin van spin core nozzle, it is the ratio between the cavity aperture diameter and exit diameter of nozzle. Due to less of the simulation model, analysis may be existence of one-sidedness. With further research, there will be a more comprehensive analysis result. Nevertheless, this superficial research is meaningful for the nozzle design.

\section{CONCLUSIONS}

(1) Twin vane spin core nozzle design in accordance with the design number of 4.1 , which can make the minimum horizontal size of the internal flow passage section not less than the exit diameter of the nozzle, and have the necessary ability of anti-water pollution, moreover the spray spread angle can reach about $50^{\circ}$.

(2) When nozzle cavity aperture is fixed, spray spread angle changes with the exit diameter almost at the direct ratio. For a certain exit diameter nozzle, increasing the cavity aperture of nozzle can improve its ability of anti-water pollution, but will reduce its spray spread angle.

\section{REFERENCES}

[1] Su-Ping Ma, Zi-ming Kou, "Design study of water pressure atomizing nozzle for spraying dust fall" [J]. Mining \& Processing Equipment, 2006, 34 (1): $67 \sim 68$

[2] Hua Zhou, Chang Zhu, Minghao Fan, "Study on the Atomization Characteristics of High-pressure Nozzle with an In-line Distributor" [J], Transactions of the Chinese Society for Agricultural Machinery, 2006, 37 (1): $63 \sim 66$

[3] Su-Ping Ma, Zi-ming Kou, "Study on mechanism of reduce dust by spray" [J], Journal of China Coal Society, 2005, 30 (3): $297 \sim 300$

[4] Shao-Xi Shi, Yu-Jing Lin, Qing Du, "Effects of spray parameters on the breakup of a swirling liquid jet" [J], Journal of Combustion Science and Technology, 1999, Volume 5 (1), pp1 6

[5] Chuan Li, Shi-Long Wang, Xian-Ming Zhang, "Numerical Investigation on Flow Field Characteristics of Nozzle with Swirl Distributor" [J], Fluid Machinery, 2007,35 (4): $19 \sim 22$

[6] Zhan-Zhong Han, Jing Wang, Xiao-Ping Lan, "FLUENT Fluid Engineering Simulation Examples and Application [M], Beijing, Beijing Institute of Technology Press, 2004.6, pp14 19

[7] Fu-Jun Wang, “ Computational Fluid Dynamics-CFD Software Principles and Applications” [M], Beijing, Tsinghua University Press, 2004.9, pp7 241 